\title{
Cerebrospinal Fluid Matrix Metalloproteinase-9 Level in Children with Bacterial Meningitis
}

\author{
AyAKO TSUMITA*1), KAORU OBINATA*1), SHIGEAKI INOUE*1), TOMOYUKI NAKAZAWA*1), \\ KENICHIRO KANEKO*1), AKIHISA OKUMURA*2), TOSHIAKI SHIMIZU*3) \\ *1) Department of Pediatrics, Juntendo University Urayasu Hospital, Chiba, Japan, *2) Department of Pediatrics, Aichi \\ Medical University, Aichi, Japan, *3) Department of Pediatrics, Juntendo University Faculty of Medicine, Tokyo, Japan
}

Objective: Cerebrovascular impairment and secondary inflammatory responses are important in bacterial meningitis-associated brain damage. The purpose of the study was to evaluate matrix metalloproteinase-9 (MMP-9) as a marker for brain damage in bacterial meningitis.

Materials: The subjects were 31 pediatric patients, including 12 with bacterial meningitis, 12 with aseptic meningitis, and 7 with other infections of the central nervous system.

Methods: Several potential markers, including MMP-9 in cerebrospinal fluid (CSF), were measured in all the pediatric patients. Results: Children with bacterial meningitis had a significantly higher level of CSF MMP-9 compared to those with other diseases aseptic meningitis and encephalitis/encephalopathy. CSF levels of MMP-9 in the 6 patients without complications markedly decreased in the recovery phase, while those of the 6 patients with complications remained high or re-elevated. CSF MMP-9 in the recovery phase was significantly higher $(\mathrm{p}<0.01)$ in patients with complications.

Conclusion: The CSF MMP-9 level may be a useful prognostic marker in pediatric patients with bacterial meningitis.

Key words: bacterial meningitis, matrix metalloproteinase-9 (MMP-9), brain damage, blood brain barrier (BBB)

\section{Introduction}

Blood brain barrier (BBB) breakdown and secondary immune and inflammatory responses mediated by direct invasion of bacteria and localized vascular impairment in the central nervous system (CNS) are thought to be involved in the pathogenesis of pediatric bacterial meningitis-associated brain damage ${ }^{1)}$. Matrix metalloproteinases (MMPs) are proteases containing a $\mathrm{Zn}^{2+}$ ion that degrade the extracellular matrix (ECM) of interstitial connective tissues and basement membranes. MMPs regulate gene expression and activation of precursor MMPs, and this activity is controlled by tissue inhibitors of metalloproteinases (TIMPs) and endogenous MMP inhibitors. MMP-9 activity is particularly associated with vascular endothelial basement membrane collagen type IV, and MMP-9 produced from glial cells injured vascular endothelial cells in the brain ${ }^{2)}{ }^{3)}$.

The extent of cortical damage is significantly associated with parenchymal gelatinolytic activity and collagen type IV degradation. Therefore, MMP-9 levels may be useful as a marker of endothelial inflammation and impairment in vasculitis. To evaluate this hypothesis, we measured the levels of MMP-9 in cerebrospinal fluid (CSF) from pediatric patients with bacterial meningitis and other CNS infections.

\section{Materials and methods}

MMP-9 levels in serum and CSF obtained from

\footnotetext{
Corresponding author: Kaoru Obinata

Department of Pediatrics, Juntendo University Urayasu Hospital

2-1-1 Tomioka, Urayasu-shi, Chiba 279-0021, Japan

TEL: +81-47-353-3111 E-mail: obinata@juntendo-urayasu.jp

〔Received Dec. 8, 2015〕〔Accepted Oct. 6, 2016〕
}

Copyright (C) 2017 The Juntendo Medical Society. This is an open access article distributed under the terms of Creative Commons Attribution License (CC BY), which permits unrestricted use, distribution, and reproduction in any medium, provided the original source is properly credited. doi: $10.14789 /$ jmj .63 .29 
12 patients (age 3 months to 6 years and 5 months old) with Bacterial meningitis, 12 patients (20 days to 13 years old) with aseptic meningitis, and 7 patients ( 1 year and 6 months to 11 years and 7 months old) with encephalitis and/or encephalopathy were measured by enzyme immunoassay (EIA). The levels of MMP-9 in serum and CSF obtained on the same day during the acute phase of bacterial meningitis were also determined in 6 cases ( 8 months to 2 years and 5 months). The correlation between CSF levels of MMP-9 and TIMP-1 in the acute phase of bacterial meningitis was examined in 8 patients ( 8 months to 3 years and 8 months). The corticosteroid therapy was performed in all cases.

\section{Results}

The mean CSF MMP-9 level in 12 patients with bacterial meningitis in the acute phase was 880.16 $\mathrm{ng} / \mu l$ (range: 73 to $2,400 \mathrm{ng} / \mu l$ ). Among the 12 patients with ascetic meningitis, CSF MMP- 9 in the acute phase ranged from 5 to $32 \mathrm{ng} / \mu l$ in 4 cases, but was $\leq 3 \mathrm{ng} / \mu l$ in 8 cases. Of the 7 patients with encephalitis or encephalopathy, CSF MMP-9 in the acute phase was $9 \mathrm{ng} / \mu l$ in 1 case, but $\leq 3 \mathrm{ng} / \mu l$ in 6 cases. In the acute phase, CSF MMP-9 in bacterial meningitis was significantly higher than in the other two groups $(\mathrm{p}<0.01$ by Mann-Whitney $\mathrm{U}$ test, Figure-1).

Of the 12 children with bacterial meningitis, 6 developed complications (subdural empyema or subdural hematoma) in the recovery phase (Table-1). CSF levels of MMP-9 in the 6 patients without complications markedly decreased in the recovery phase (Figure-2), while those of the 6 patients with complications remained high or re-elevated. CSF MMP-9 in the recovery phase was significantly higher in patients with complications ( $\mathrm{p}<0.01$ by Mann-Whitney U test).

There was no correlation $(r=-0.23)$ between CSF and serum MMP-9 levels in 6 patients with bacterial meningitis in the acute phase (Figure-3). There was also no correlation $(r=-0.63)$ between CSF MMP-9 and TIMP-1 levels in 9 patients with bacterial meningitis in the acute phase (Figure-4).

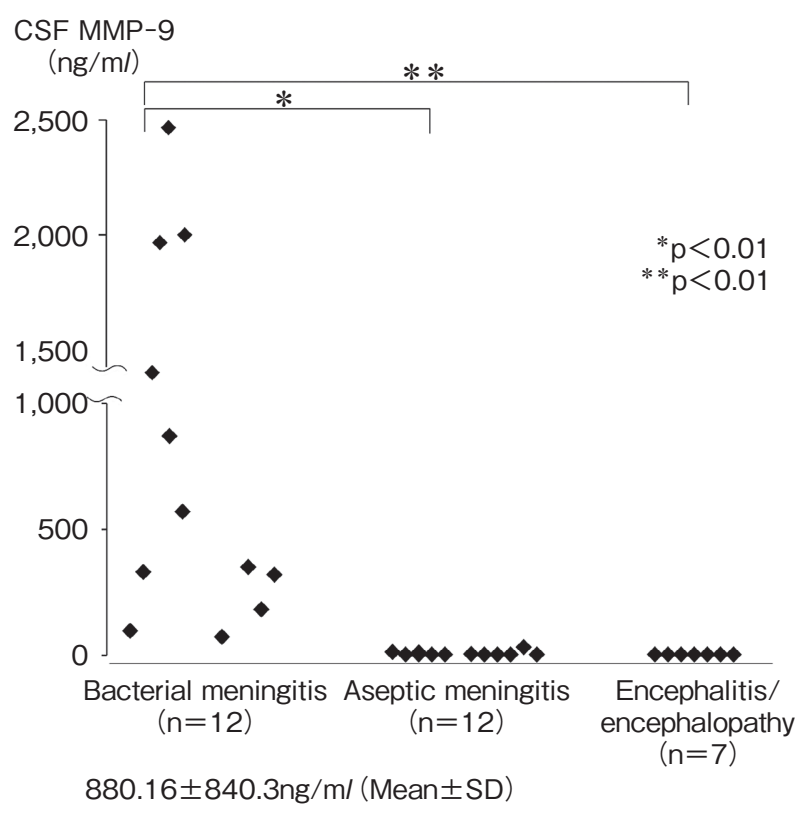

Figure-1 Comparison of MMP-9 levels in cerebrospinal fluid (CSF)

Table-1 Twelve cases with bacterial meningitis

\begin{tabular}{cccccc}
\hline Case & Age & CSF cell count & $\begin{array}{c}\text { Pathogenic } \\
\text { microorganism }\end{array}$ & $\begin{array}{c}\text { Intracranial } \\
\text { fluid retention }\end{array}$ & Complications Sequelae \\
\hline 1 & 3 у 2 mo & 8,810 & H. influenzae & - & no \\
2 & 2 у 5 mo & 5,497 & H. influenzae & - & no \\
3 & 1 y 2 mo & 1,444 & H. influenzae & - & no \\
4 & 3 у 8 mo & 10,170 & H. influenzae & - & no \\
5 & 6 у 5 mo & 12,500 & H. influenzae & - & no \\
6 & 1 у 5 mo & 6,402 & S. pneumoniae & - & no \\
7 & 8 mo & 782 & H. influenzae & + & Epilepsy, Paralysis \\
8 & 6 mo & 1,408 & H. influenzae & + & Epilepsy \\
9 & 3 mo & 3,922 & H. influenzae & + & no \\
10 & 11 mo & 1,553 & H. influenzae & + & Developmental retardation \\
11 & 1 у 1 mo & 640 & H. influenzae & + & Hearing loss \\
12 & 9 mo & 25,000 & H. influenzae & + & no \\
\hline
\end{tabular}



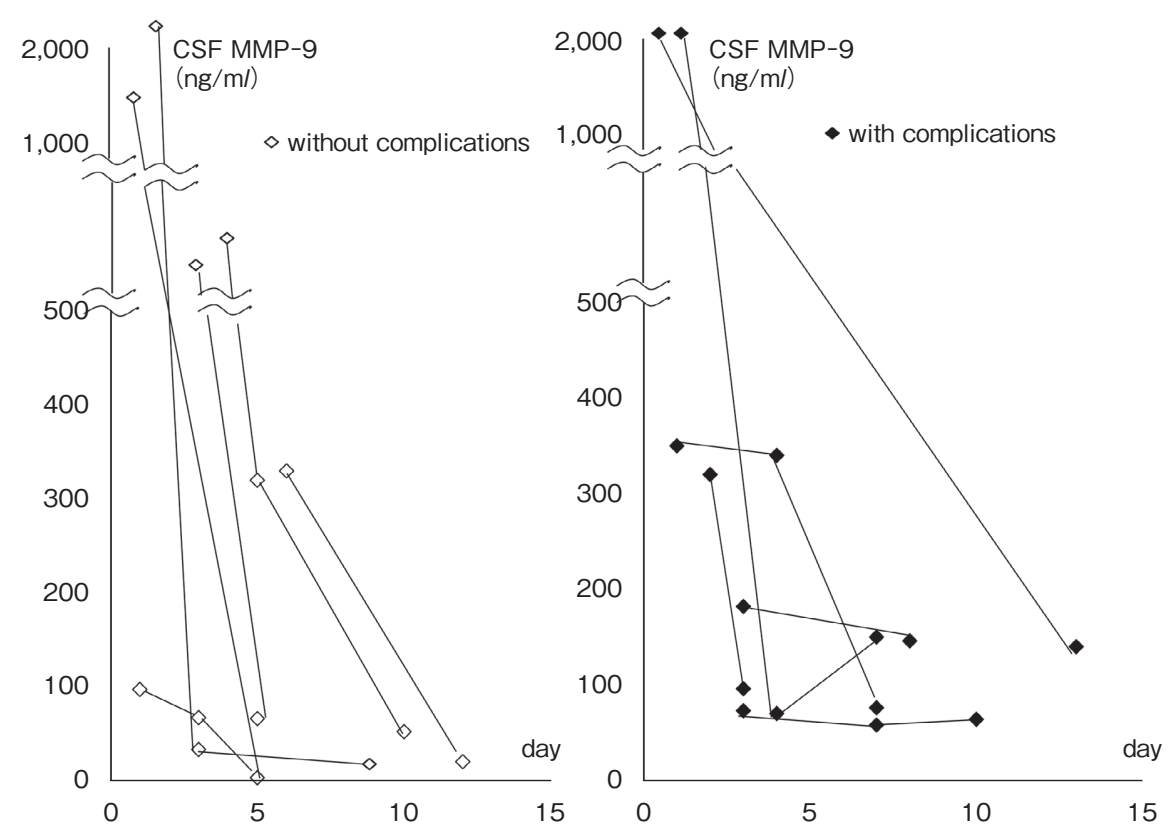

Figure-2 CSF MMP-9 levels in bacterial meningitis without complications and with complications

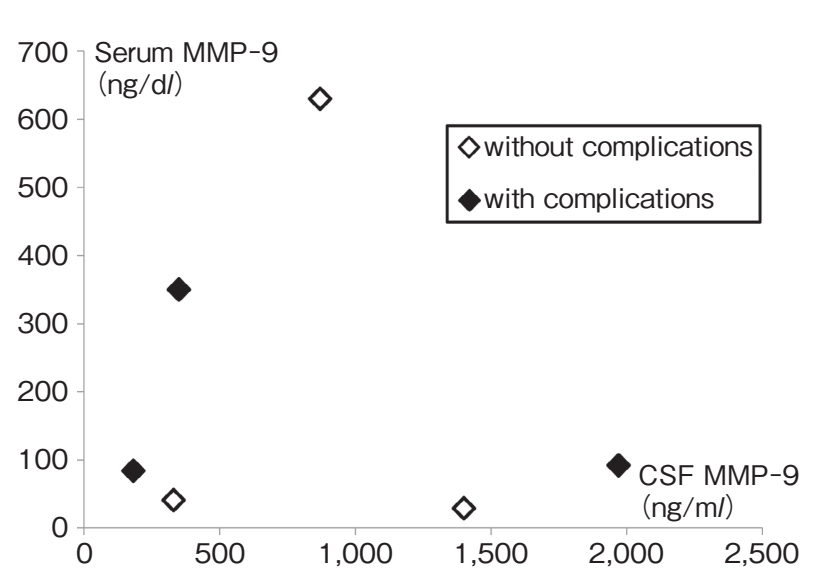

Figure-3 Serum MMP-9 and CSF MMP-9 levels in bacterial meningitis

CSF MMP9/TIMP1 ratio

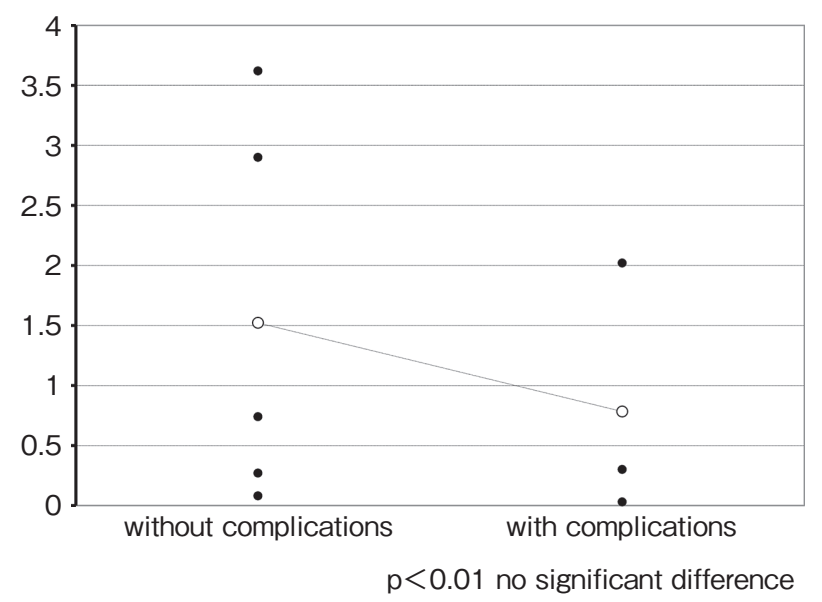

Figure-5 CSF MMP-9/TIMP-1 ratio in bacterial meningitis

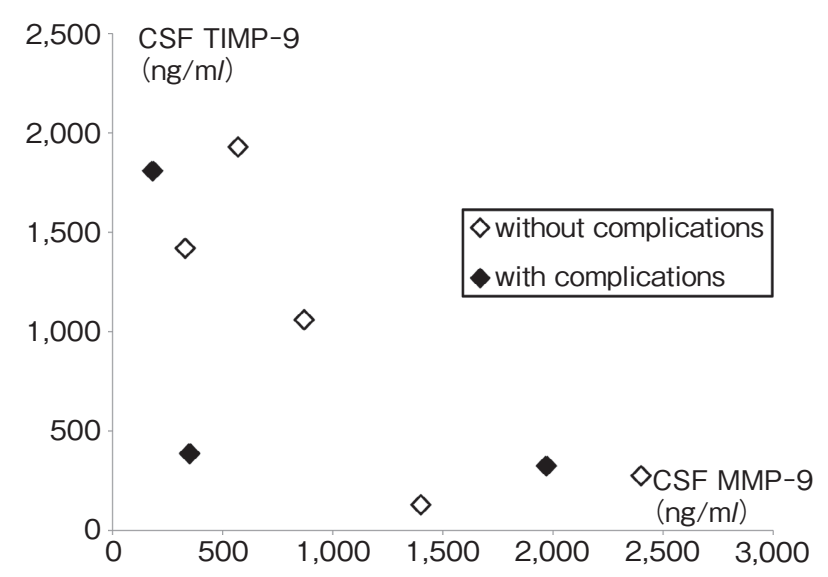

Figure-4 CSF TIMP-1 and CSF MMP-9 levels in bacterial meningitis

MMP/TIMP ratio in bacterial meningitis patients was no significant difference between with complications and without complications $(\mathrm{p}<0.01$ by Unpaired $t$ test) (Figure-5).

\section{Discussion}

Bacterial meningitis-associated brain damage is ${ }^{4)}$ thought to be due to inflammatory infiltration cytokine and/or chemokine-induced BBB breakdown, rather than direct bacterial invasion of brain tissues. MMP-9 is found in tissues, cells and blood, and can decompose gelatin and a component of the ECM, collagen type IV. An increase in the MMP-9 level causes damage to the vascular endothelium. In 
the current study, a significantly higher level of MMP-9 was found in the CSF of children with bacterial meningitis in the acute phase, compared to children with ascetic meningitis and encephalitis or encephalopathy. There was no correlation between CSF-MMP9 and serum MMP-9 (Figure-3), total cell and neutrophil counts in terms of complication (Figure not shown).

Therefore, MMP-9 produced in the CSF but not from serum is likely to enhance BBB permeability and induce $\mathrm{BBB}$ breakdown during the acute phase of bacterial meningitis, resulting in intrathecal invasion of inflammatory substances and leads to basement membrane damage. Therefore, basement membrane damage may occur in the vascular endothelium of the brain. A high protracted level of MMP-9 may lead to development of brain damage based on the persistent increased CSF MMP-9 level in patients with bacterial meningitis-associated brain damage. These results suggest that MMP-9 may be a marker for quantitative assessment of vascular impairment in the CNS.

TIMPs are inhibitors of MMP activity that bind to the active site of MMP. An increase in the level of MMPs relative to TIMPs (MMP/TIMP ratio) can cause chronic rheumatoid arthritis, coronary artery lesions with Kawasaki disease, and cancer invasion and metastasis due to tissue destruction and increased tissue fragility ${ }^{6-8)}$. TIMPs are profibrotic agents that have a role in development of scarring in different organs, with scleroderma, pulmonary fibrosis, and nephrosclerosis resulting from tissue infiltration and ECM accumulation induced by a decreased serum MMP/TIMP ratio at onset ${ }^{9)-12}$. We have no data on serum MMP/TIMP ratio in this study, however we found no correlation of the CSF-MMP9/TIMP ratio at onset with disease activity. There was also no correlation between CSF and serum MMP-9 levels in the acute phase of bacterial meningitis. This suggests that CSF MMP-9 is produced mainly in the $\mathrm{CNS}^{13)}$ and evokes vascular endothelial cell damage in the brain. CSF MMP-9 levels have been suggested to be correlated with cells counts in $\mathrm{CSF}^{14)}$, but in our 12 patients with bacterial meningitis CSF MMP-9 levels were not correlated with total cell and neutrophil counts in the CSF (correlation coefficient: $r=-0.22)$ or with clinical severity. When bacteria invades the CSF, neutrophils are activated and upregulate production of neutrophil elastase. Monocytes and cytokines may also cause activation of MMP-9 in neutrophils, which destroy the ECM on the vascular endothelial basement membrane. These results in enhancement of the permeability of the vascular endothelium, causing BBB breakdown, influx of inflammatory cells and blood substances, and development of subdural lesions. Therefore, MMP-9 in the CSF may contribute to BBB breakdown directly ${ }^{15)}$ 16).

As a result of our experiment, CSF MMP-9 in the recovery phase of Bacterial meningiits was significantly higher in patients with complications. But CSF TNF $\alpha$ in the 5 cases of bacterial meningitis was not correlated with their prognosis (data not shown). Thus, high CSF MMP-9 seems to be a more useful marker that reflects the degree of brain damage associated with bacterial meningitis and the prognosis, relative to other cytokines. A high CSF MMP-9 level appears to be a cause of bacterial meningitis-associated brain damage, and CSF MMP-9 may be a qualitative marker for the prognosis of this disease.

\section{Conflicts of interest}

The authors declare no conflict of interest associated with this manuscript.

\section{References}

1) Pastuszka E, Pabin A, Radkowski M: Metalloproteinases in meningoencephalitis. Przegl Epidemiol, 2008; 62: 401406.

2) Scheld WM, Koedel U, Nathan B, Pfister HW: Pathophysiology of bacterial meningitis: mechanism(s) of neuronal injury. J Infect Dis, 2002; 186 Suppl 2: S225233.

3) Zhang H, Adwanikar H, Werb Z, Noble-Haeusslein LJ: Matrix metalloproteinases and neurotrauma: evolving roles in injury and reparative processes. Neuroscientist, 2010; 16: 156-170.

4) Mustafa MM, Lebel MH, Ramilo O, et al: Correlation of interleukin-1 beta and cachectin concentrations in cerebrospinal fluid and outcome from bacterial meningitis. J Pediatr, 1989; 115: 208-213.

5) Fritz D, Brouwer MC, van de Beek D: Dexamethasone and long-term survival in bacterial meningitis. Neurology, 2012; 79: 2177-2179.

6) Cunnane G, Fitzgerald O, Beeton C, Cawston TE, Bresnihan B: Early joint erosions and serum levels of matrix metalloproteinase 1, matrix metalloproteinase 3, and tissue inhibitor of metalloproteinases 1 in rheumatoid arthritis. Arthritis Rheum, 2001; 44: 2263-2274. 
7) Ikeda K, Ihara K, Yamaguchi K, et al: Genetic analysis of MMP gene polymorphisms in patients with Kawasaki disease. Pediatr Res, 2008; 63: 182-185.

8) Lu H, Cao X, Zhang H, et al: Imbalance between MMP-2, 9 and TIMP-1 promote the invasion and metastasis of renal cell carcinoma via SKP2 signaling pathways. Tumour Biol, 2014; 35: 9807-9813.

9) Sellner J, Leib SL: In bacterial meningitis cortical brain damage is associated with changes in parenchymal MMP-9/TIMP-1 ratio and increased collagen type IV degradation. Neurobiol Dis, 2006; 21: 647-656.

10) Meng C, Chen X, Li J, Wu Y, Liu H: Expression of MMP-9 and TIMP-1 in lesions of systemic sclerosis and its implications. J Huazhong Univ Sci Technolog Med Sci, 2008; 28: 480-482.

11) Lagente V, Manoury B, Nénan S, Le Quément C, MartinChouly C, Boichot E: Role of matrix metalloproteinases in the development of airway inflammation and remodeling. Braz J Med Biol Res, 2005; 38: 1521-1530.

12) Chromek M, Tullus K, Lundahl J, Brauner A: Tissue inhibitor of metalloproteinase 1 activates normal human granulocytes, protects them from apoptosis, and blocks their transmigration during inflammation. Infect Immun, 2004; 72: 82-88.

13) Wang HH, Hsieh HL, Yang CM: Calmodulin kinase IIdependent transactivation of PDGF receptors mediates astrocytic MMP-9 expression and cell motility induced by lipoteichoic acid. J Neuroinflammation, 2010; 7: 84.

14) Yushchenko M, Weber $F$, Mäder $M$, et al: Matrix metalloproteinase-9 (MMP-9) in human cerebrospinal fluid (CSF): elevated levels are primarily related to CSF cell count. J Neuroimmunol, 2000; 110: 244-251.

15) Roine I, Pelkonen T, Bernardino L, et al: Predictive value of cerebrospinal fluid matrix metalloproteinase -9 and tissue inhibitor of metalloproteinase-1 concentrations in childhood bacterial meningitis. Pediatr Infect Dis J, 2014; 33: $675-659$

16) Leppert D, Leib SL, Grygar C, Miller KM, Schaad UB, Holländer GA: Matrix metalloproteinase (MMP) -8 and MMP-9 in cerebrospinal fluid during bacterial meningitis: association with blood-brain barrier damage and neurological sequelae. Clin Infect Dis, 2000; 31: 80-84. 